\title{
A neural field model using advanced anatomical connectivity information
}

\author{
Christopher Koch ${ }^{1,2^{*}}$, Manh Nguyen Trong ${ }^{1,2}$, Andreas Spiegler ${ }^{1,2}$, Thomas R Knösche ${ }^{1}$ \\ From Twentieth Annual Computational Neuroscience Meeting: CNS*2011 \\ Stockholm, Sweden. 23-28 July 2011
}

We propose a mathematical framework for a neural field model that can accommodate empirical information on connectivity strength between different parts of the brain, and axonal caliber information of these connections. Furthermore, we use integro-differential equations to describe the mean dynamics (i.e., firing rate and mean membrane potential) [1]. We demonstrate the framework at the example of the rat brain.

Here, we specify the propagation velocity distributions by a linear relationship using empirical, position-variant, axonal diameter distributions of myelinated and unmyelinated callosal axons [2]. We approximate the
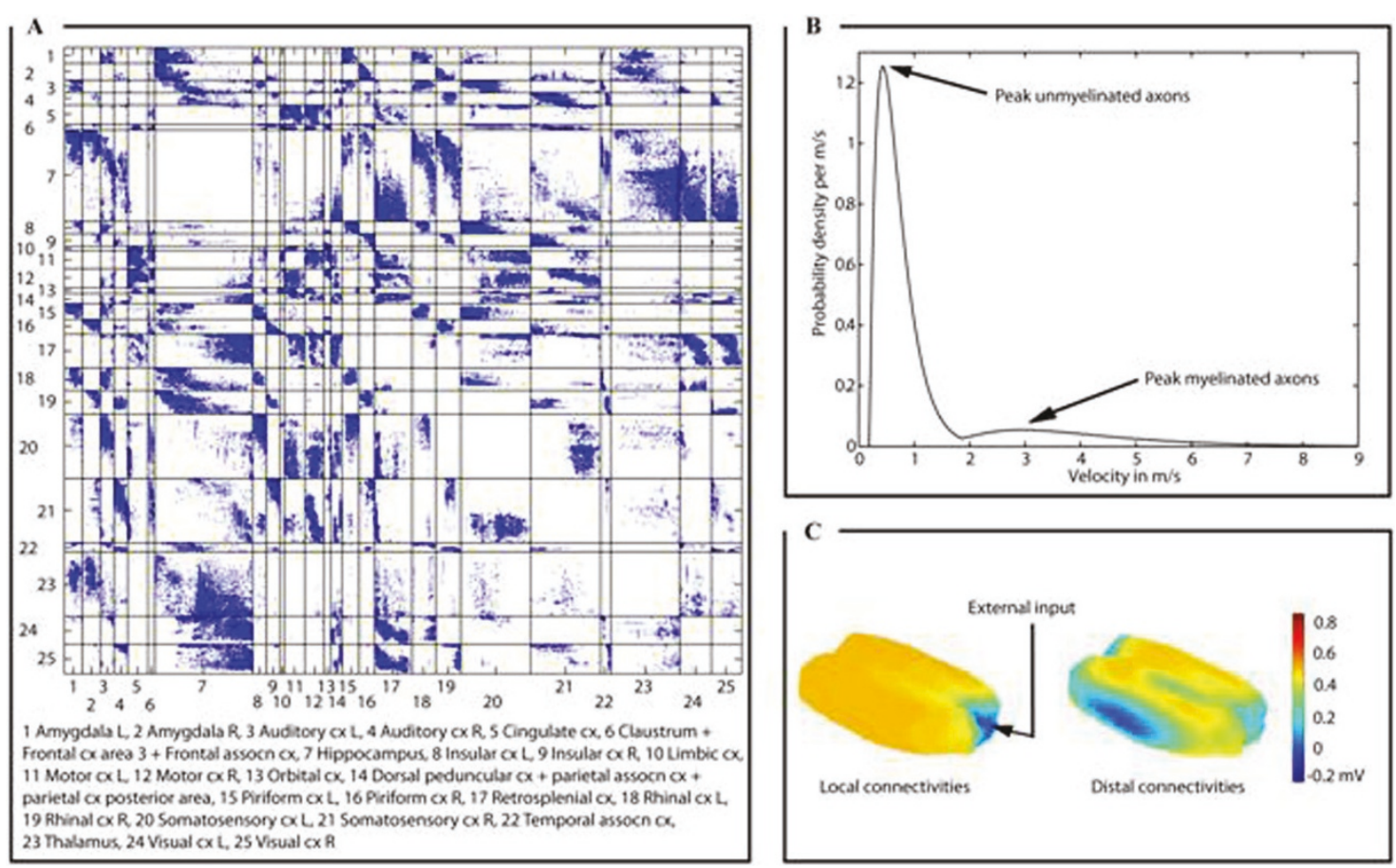

Figure 1 A. Connectome B. Velocity probability density C. Electrocorticogram

\footnotetext{
* Correspondence: christopher_koch@live.de

${ }^{1}$ Max Planck Institute for Human Cognitive and Brain Sciences, Leipzig, Germany

Full list of author information is available at the end of the article
} 
experimentally estimated histograms of axonal diameters using alpha functions. By interpolating these alpha functions in space, weighted by the fiber densities of the myelinated and unmyelinated axons, we compute the velocity probability density (see Figure 1B). Diffusion tensor imaging is used to reconstruct axonal projections through the white matter. We use an atlas-based parcellation of the rat brain [3] to allocate the reconstructed projections to specific brain regions, yielding a connectome (see Figure 1A). The structures that are most strongly interconnected are the hippocampus, the thalamus, the motor and the sensory cortices. A simulation of the electrocorticogram demonstrates the impact of distal over local connections on brain function (see Figure $1 \mathrm{C})$.

\section{Author details}

'Max Planck Institute for Human Cognitive and Brain Sciences, Leipzig, Germany. ${ }^{2}$ Institute for Biomedical Engineering and Informatics, IImenau University of Technology, Ilmenau, Germany.

Published: 18 July 2011

\section{References}

1. Atay F, Hutt A: Stability and bifurcations in neural fields with finite propagation speed and general connectivity. SIAM J. Appl. Math 2005, 65(2):644-666.

2. Partadiredja G, Miller R, Oorschot DE: The number, size, and type of axons in rat subcortical white matter on left and right sides: A stereological, ultrastructural study. Journal of Neurocytology 2003, 32:1165-1179.

3. Paxinos G, Watson C: The Rat Brain in Stereotaxic Coordinates. San Diego, Academic Pres;" 62007.

\section{doi:10.1186/1471-2202-12-S1-P174}

Cite this article as: Koch et al:: A neural field model using advanced anatomical connectivity information. BMC Neuroscience 2011 12(Suppl 1): P174.

\section{Submit your next manuscript to BioMed Central} and take full advantage of:

- Convenient online submission

- Thorough peer review

- No space constraints or color figure charges

- Immediate publication on acceptance

- Inclusion in PubMed, CAS, Scopus and Google Scholar

- Research which is freely available for redistribution

Submit your manuscript at www.biomedcentral.com/submit 